\title{
THE RECURRENCE OF INTRACRANIAL MENINGIOMAS AFTER SURGICAL TREATMENT
}

\author{
BY \\ DONALD SIMPSON
}

\author{
From the Department of Neurological Surgery, Radcliffe Infirmary, Oxford
}

The meningiomas are justly considered to be among those intracranial tumours most amenable to treatment, and if the difficulties, often formidable, attending their removal can be overcome, there is good prospect of a permanent cure. However, in occasional cases, late recurrences do take place, even after resections appearing entirely satisfactory to the surgeon responsible. This is not a common misfortune, but neither is it rare enough to be negligible. Considerable interest attaches to the tumours which recur after seemingly adequate treatment. They present important practical problems in prophylaxis and in management. And they are most instructive as studies in the biology of the meningiomas generally.

Most neurosurgeons have experienced the disappointment of such recurrences. Horsley (1893), Ballance (1907), and Krause (1910-12), while stressing the innocence of the tumours they designated fibromas, endotheliomas, or dural sarcomas, all mention their occasional unexpected recurrence. Initially, little importance was attached to these recurrences, but as neurosurgical technique improved and the number of survivals increased, they attracted more attention. Craig, in 1927, first emphasized the variations in the natural history of the meningiomas, and separated a group whose histology and behaviour he considered frankly malignant. Taylor (1928) also challenged contemporary belief in the innocence of the meningiomas. It was, however, in the great monograph of Cushing (1938) that the behaviour of the meningiomas and their disposition to recur were most fully discussed. Cushing apparently began his surgical career with the conviction that the meningiomas are highly benign tumours: he ultimately came to treat them with the greatest respect, as prone to infiltrate locally and to recur from such infiltrations. In 43 of his 295 cases, reoperation for " actual or symptomatic" recurrence was necessary, and 76 patients died at home with incompletely removed tumours. Cushing unfortunately does not state the incidence of recurrence after operations which had appeared to him as total removals: but analysis of his tabulated cases suggests that it was not less than $15 \%$. He and Eisenhardt presented a complex histological classification, which was specifically intended as a guide to the biological behaviour of the tumours, but they nevertheless recognized the limitations of the histological assessment.

This monograph remains the prime source for any study of the meningiomas. Since its publication there have been a number of reports on the moderno treatment of meningiomas; in most of these the development of recurrence is mentioned. There hasD been at least one study devoted solely to this problems (Volynkin, 1955). Much has been written on the pathology of the meningiomas, and especially op their occasional malignancy. A review of the large body of literature suggests, however, that there is $\vec{\varphi}$ still difference of opinion on several questions of $\mathrm{G}$ fundamental importance.

(1) There is no agreement on the frequency or significance of recurrence. Very few contemporary surgeons have given the incidence of recurrence in their material. Olivecrona (Olivecrona, 1947; Hoessly and Olivecrona, 1955) thought that with his parasagittal meningiomas the recurrence rate was under $10 \%$; his figures are, however, admittedly incomplete, since they do not comprehend patients dying at home. Grant (1954) reported 13 delayed deaths due to tumour growth in 219 cases, all after " incomplete removals ". He refers to these fatalities as deaths from recurrence, and very properly, since one may speak of a symptomatic recurrence even after an operation known to have been incomplete. But it is not possible to determine from his account whether these "incomplete removals" had been recognized as such initially, or whether they had appeared complete resections at the original operation. This is a crucial distinction. The same uncertainty vitiates (for this particular purpose) the report of Horrax and Strain (1952), who mention nine fatal recurrences in 168 cases. Moreover, in neither 
report is it clear how many non-fatal recurrences were encountered. There is also great difference in the emphasis attached to the problem: some pass it over as of little moment, while others, like Fincher (1954), lay very great weight on it.

(2) There is also much uncertainty as to the causes of recurrence, especially their relative importance. It is generally agreed that some meningiomas are clinically malignant, as witnessed by rapid growth, invasive tendency, and, rarely, extracranial metastasis. Winkelman, Cassel, and Schlesinger (1952) found 10 acceptable examples of metastasis, to which may be added the cases reported by Christensen, Klaer, and Winblad (1949), Swingle (1949), Laymon and Becker (1949), Cross and Cooper (1952), Shozawa (1952), Zülch, Pompeu, and Pinto (1954), Rosen and Branch (1954), and Lima (1951), in all at least 19. But whether in practice clinical recurrences are more likely to result from the intrinsic malignancy of the tumours, rather than from the inadequacy of the surgical resections, is still disputable.

(3) There is no unanimity on the biological significance attachable to the histological appearances in a given tumour. Thus, Turner, Craig, and Kernohan (1942) claim a close correlation between clinical course and histology, whereas Folke Henschen (1955) found no constant relationship. The possibility that microscopic assessment may be supplemented by study of the angioarchitecture of the living tumour, as seen in angiograms, is also controversial. If a definite assessment of the potentialities of a particular tumour could be made, and its liability to recur were considered high, the propriety of carrying out a more radical resection would arise, and perhaps even of prophylactic irradiation, though these tumours are not generally considered radio-sensitive (McWhirter and Dott, 1955).

Some of these differences of opinion are differences only in emphasis without basic disagreement. Others, however, are more profound, and raise issues relevant to the operative treatment of the meningiomas. Moreover-and few writers have given this its due prominence-a just appreciation of the natural history of the disease is essential in post-operative management. The likelihood that a given tumour will recur must be kept in mind, because recurrent meningiomas may present serious diagnostic difficulties. This is particularly so when the only symptom is epilepsy and the bulk of the tumour is insufficient to distort the ventricular or arterial anatomy, as may occasionally be the case. It seems therefore worth while to present the conclusions derived from a study of the problem of recurrence begun several years ago, out of concern at the apparent frequency of recurrence with meningiomas, especially those in the parasagittal group.

\section{Material}

Between April, 1938, and December, 1954, 242 cases of intracranial meningioma were treated in the Department of Neurological Surgery at the Radcliffe Infirmary, excluding patients with spinal and primary intraorbital meningiomas. In all, the diagnosis was confirmed either at operation or at necropsy; in all save two verification by microscopy has been obtained and reviewed by the writer. These patients are the basis of the investigation reported here. They are referred to as the Oxford series.

When the analysis of this series was completed, it was realized that the lack of any cases surviving more than 17 years was a serious drawback. For this reason, the intracranial meningiomas treated by Sir Hugh Cairns when in London, between 1928 and 1938, have also been considered. There were 97 of these. However, they were found to constitute less satisfactory material. This was partly because of difficulties in following the patients up, and partly because the tumours seem to a degree a selected group, malignant behaviour being unduly rare with them. They have therefore been separately designated as the London series, and only limited use has been made of them.

The material thus available can be examined from two aspects. First, the analysis of the ultimate fates of those patients surviving operation gives the incidence of recurrence and its practical significance. For this purpose, the survivors in both series have been considered, and their fates determined. This was an unexpectedly difficult enterprise. It has been possible to trace all the cases of the Oxford series, though in two the information obtained is meagre. The patients in the London series were more elusive, many having been dispersed by the war, and 10 have not been found. It is very probable that some of those still missing are living yet, but it seems best to exclude them. Second, the pathological findings, both operative and at necropsy, in the Oxford series have been personally reviewed. Analysis of all these gives a background against which the pathology of those tumours which have recurred can be studied. Clinical data relevant to the prophylaxis of recurrence have been taken from the Oxford series, and are briefly considered in conclusion.

\section{Terminology}

As far as possible Cushing's (1938) terminology has been used. His method of regional classification has also been employed, save in that no separate identification of the few peritorcular tumours has 
seemed needful. Table I shows the incidence according to this system, with, for comparison, the series published by Cushing (1938) himself and by Olivecrona (1947). More controversial is the definition of what constitutes a meningioma. It is, after all, merely a term of convenience, without any precise histogenetic implication. Some pathologists extend it to comprehend diffusely spreading non-gliomatous

TABLE I

REGIONAL INCIDENCE

\begin{tabular}{|c|c|c|c|c|}
\hline Site & $\begin{array}{l}\text { London } \\
\text { Series }\end{array}$ & $\begin{array}{l}\text { Oxford } \\
\text { Series }\end{array}$ & $\underset{\text { (1938) }}{\text { Cushing }}$ & $\begin{array}{l}\text { Olive- } \\
\text { crona } \\
\text { (1947) }\end{array}$ \\
\hline \multirow{2}{*}{$\begin{array}{l}\text { Posterior fossa } \\
\text { Subtemporal } \\
\text { Sphenoid ridge } \\
\text { (a) global } \\
\text { (b) enplaque } \\
\text { Suprasellar } \\
\text { Olfactory groove } \\
\text { Convexity } \\
\text { Parasagittal and peritorcular } \\
\text { Falx } \\
\text { Intraventricular } \\
\text { Other }\end{array}$} & $\begin{array}{l}8 \\
1\end{array}$ & $\begin{array}{r}27 \\
8\end{array}$ & $\begin{array}{r}28 \\
8\end{array}$ & $\begin{array}{l}72 \\
17\end{array}$ \\
\hline & $\begin{array}{r}14 \\
2 \\
7 \\
12 \\
20 \\
27 \\
2 \\
2 \\
2\end{array}$ & $\begin{array}{r}32 \\
9 \\
14 \\
14 \\
47 \\
80 \\
6 \\
4 \\
1\end{array}$ & $\begin{array}{r}37 \\
16 \\
28 \\
29 \\
54 \\
77 \\
7 \\
4 \\
6\end{array}$ & $\begin{array}{r}96 \\
15 \\
42 \\
46 \\
91 \\
143 \\
62 \\
18 \\
6\end{array}$ \\
\hline \multirow{2}{*}{ Totals } & 97 & 242 & & \\
\hline & \multicolumn{2}{|c|}{339} & 294 & 608 \\
\hline
\end{tabular}

malignant tumour (cf. Globus, Levin, and Sheps, 1944). Others narrow it by excluding the angioblastic tumours (cf. Kernohan and Sayre, 1952). Here, in an attempt to conform with ordinary clinical usage, the term is applied to those circumscribed tumours with meningeal or choroidal attachment, whose histology suggests, or is at least compatible with, an origin from the cells of the arachnoid villi. This is to include tumours composed of endothelial cells, fibroblastic tumours, and vasoformative tumours, however anaplastic. Two clinically malignant connective tissue tumours have been excluded because, though they were not of gliomatous character nor metastatic, it was not possible to say from what mesenchymal tissue they arose.

Finally, the term " recurrence " is used in a purely clinical sense to imply the reappearance of symptoms due directly to tumour growth after a period of symtomatic relief. So used, it has no pathological specificity, and though of course such a recurrence usually means the continued growth of an incompletely excised tumour, yet it may also be extended to cover patients whose symptoms return because of a second primary meningioma. It is not always possible in a given case to decide which process is responsible.

\section{Frequency of Recurrence}

In the Oxford series, 235 cases came to operation; in the remainder, only diagnostic procedures were carried out. Thirty $(13 \%)$ died within six̀ months. This figure overestimates the real surgical mortality, since it comprehends a few patients dying from intercurrent disease or continued tumour growth after their discharge from hospital. But for the present purpose, survivals of less than six months cannot be considered as worth-while clinical remissions, and they are therefore excluded. In the earlier London series, the operative mortality was naturally greater, and only 70 patients survived more than six months. Of these, 10 are excluded because untraced, leaving in the two series together 265 patients in whom the possibility of recurrence can arise.

It seems that 55 of these patients have developed symptomatic recurrences, 44 in the Oxford series and 11 in the London series. It is true that histological verification, from biopsy or necropsy, is lacking in 21 instances. These are mainly patients dying at home or in other centres, whose ceaths were certified as due to intracranial tumour. Some doubt must arise as to the accuracy of such certification. Hoessly and Olivecrona (1955), faced with the same problem, thought it impossible to sift the deaths by recurrence from those due to unrelated disease. I have, however, felt it wisest to accept the opinion of the attendant physician, amplified where possible by personal enquiry, though with some reservations in four cases. To offset this possibility of error, it is very probable that several of the 10 cases untraced also died of recurrence. I believe, therefore, that this estimate is substantially correct, and that in the combined series the incidence of recurrence is about $21 \%$.

This is a high incidence, and becomes even higher if cases treated recently are excluded. It is, however, inflated by the inclusion of recurrence developing after resections known to have been incomplete. These are symptomatic recurrences as here defined, but their significance is much less than that of recurrences after apparently complete removals, and it is necessary to analyse the operative procedures more minutely.

Some were thought by the surgeon to be complete; some were extensive but left aside small residua; some were frankly incomplete. From the very detailed descriptions recorded by Sir Hugh Cairns, Mr. J. Pennybacker, and their assistants, it is possible to identify five fairly distinct grades of operation.

Grade I.-This is a macroscopically complete removal of the tumour, with excision of its dural attachment, and of any abnormal bone. Where the tumour arises from the wall of a dural venous sinus, such an operation necessarily entails resection of the sinus.

Grade II.-This denotes a macroscopically 
complete removal of the tumour and of its visible extensions, with endothermy coagulation (usually to the point of charring) of its dural attachment.

Grade III.-This denotes a macroscopically complete removal of the intradural tumour, without resection or coagulation of its dural attachment, or alternatively, of its extradural extensions, e.g., an invaded sinus or hyperostotic bone.

Grade IV.- This denotes a partial removal, leaving intradural tumour in situ.

Grade V.-This is a simple decompression, with or without biopsy.

Such a subdivision may be thought overelaborate. But it is essential that some distinction between operations of varying scope should be made, and this seems a convenient, even a natural, grading. It is of course true that the surgeon's assessment is not always correct, especially with the deeper tumours. However, the main purpose of this investigation is the study of the unforeseen, usually unforseeable, recurrence, and therefore the operative impression, sometimes modified by examination of the excised specimen, must be the standard.

An operation of Grade $I$ is radical treatment. It was possible to carry out such operations with most of the tumours of the cerebral (or cerebellar) convexity, since their dural attachments are accessible and unrelated to a major venous sinus. Less than a quarter of the parasagittal and falx tumours were so treated. With the parasagittal tumours an operation of Grade I entailed resection of the superior longitudinal sinus, and usually a complete resection, although it was rarely found sufficient to do a marginal resection without total occlusion of the sinus. The dangers of resecting the patent sinus are well known. The primary tumours of the falx, by definition, do not arise from the walls of the sagittal sinus and may never encroach on them; even so, there is a natural reluctance to excise the free falx opposite the striate cortex or the paracentral lobule. Grade I operations were very rarely possible with tumours of the sphenoidal ridge, posterior fossa, olfactory groove, and suprasellar region. In all, 90 operations of this grade were carried out; in 81 cases these were primary operations, and in nine operations on recurrent tumours. There have been eight recurrences after operations of this grade, seven verified and one rather questionable.

Fig. 1 shows their regional distribution. Two tumours of the sphenoidal ridge recurred, although their dural attachments had been stripped off, and all suspicious bone nibbled away. Two parasagittal meningiomas, one already recurrent after less radical surgery, have recurred despite block resection of sinus and falx. Two tumours of the cerebral convexity are thought to have recurred: in one the recurrence was verified at operation, but in the other, a case in the London series dying 12 years after the original resection, there is some doubt over the diagnosis. A tumour of the cerebellar convexity has recurred twice. The incidence even after this radical procedure, which would appear to meet the surgical ideal for these tumours, is thus $9 \%$. If cases treated in the last five years are excluded, the incidence is unchanged, because two recent cases have already recurred. It is nevertheless reasonable to assume that this figure of $9 \%$ is a minimum estimate, and that a few other tumours in this group will eventually recur. The average time elapsing between primary operation and confirmation of recurrence was 62 months in the verified cases, the longest interval being $13 \frac{1}{2}$ years and the shortest 13 months.

Operations of Grade II are usually considered as satisfactory treatment. But it is clear that to rely on the diathermy coagulation as a destructive agent is to admit an uncertain factor. One patient in the Oxford series died in a road accident a year after the removal of an olfactory groove meningioma. Necropsy showed no visible tumour remnants. The dural attachment, which had been carefully coagulated, was examined in serial sections, and no tumour cells were found. But in the underlying bone nests of viable meningioma tissue were clearly seen. For what it is worth, this suggests that the diathermy coagulation is able to deal efficiently with invasion of the dura mater, but that it will not sterilize any more remote spread. And this accords with clinical experience.

Grade II resections were carried out on 114 occasions (107 primary operations and seven operations for recurrent tumours). Most of the parasagittal meningiomas were so treated (Table II). Grade II resection was the only radical procedure possible with the tumours of the olfactory groove, and with

TABLE II

RADICAL OPERATIONS AND INCIDENCE OF RECURRENCE IN DIFFERENT SITES (COMBINED SERIES)

\begin{tabular}{|c|c|c|c|c|c|c|}
\hline \multirow[b]{2}{*}{ Site } & \multicolumn{3}{|c|}{ Grade I } & \multicolumn{3}{|c|}{ Grade II } \\
\hline & $\begin{array}{l}\text { No. of } \\
\text { Opera- } \\
\text { tions }\end{array}$ & $\begin{array}{l}\text { No. of } \\
\text { Recur- } \\
\text { rences }\end{array}$ & $\begin{array}{l}\% \\
\text { Recur- } \\
\text { rence }\end{array}$ & $\begin{array}{c}\text { No. of } \\
\text { Opera- } \\
\text { tions }\end{array}$ & $\begin{array}{l}\text { No. of } \\
\text { Recur- } \\
\text { rences }\end{array}$ & $\begin{array}{l}\% \\
\text { Recur- } \\
\text { rence }\end{array}$ \\
\hline $\begin{array}{l}\text { Parasagittal and } \\
\text { falx }\end{array}$ & 21 & 2 & 5 & 69 & 12 & 17 \\
\hline $\begin{array}{l}\text { Convexity and in- } \\
\text { traventricular }\end{array}$ & 58 & $\begin{array}{l}2 \\
\text { (1 du- } \\
\text { bious) }\end{array}$ & 3.5 & 6 & 1 & 17 \\
\hline $\begin{array}{l}\text { Basal } \\
\text { Sphenoidal ridge } \\
\text { Subfrontal } \\
\text { Subtemporal } \\
\text { Posterior fossa }\end{array}$ & $\begin{array}{l}11 \\
(7) \\
(1) \\
(0) \\
(3)\end{array}$ & $\begin{array}{l}4 \\
(2) \\
(0) \\
(0) \\
(2)\end{array}$ & 36 & $\begin{array}{l}39 \\
(10) \\
(13) \\
(1) \\
(13)\end{array}$ & $\begin{array}{l}5 \\
(2) \\
(1) \\
(0) \\
(2)\end{array}$ & 13 \\
\hline
\end{tabular}


OPERATIONS OF

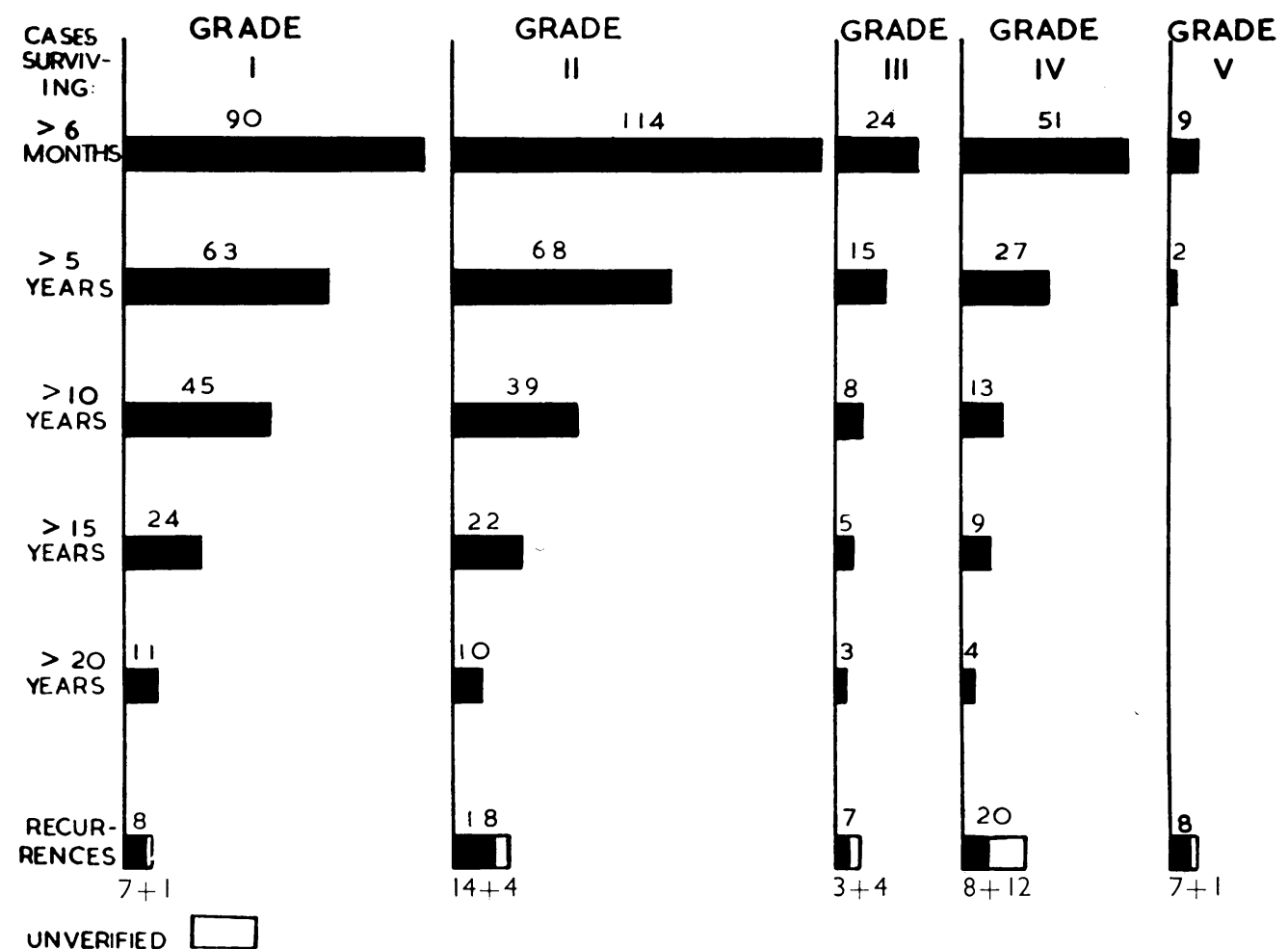

FIG. 1.-Diagram showing operation grading, survival time, and frequency of recurrence in the combined Oxford and London series. All are patients surviving six months or more and known to have been alive and well at or after Christmas, 1953.

all save one of the suprasellar tumours: this was so because the removal of their dural attachments would have laid bare the ethmoid air cells. It was also the procedure of expediency with most of the tumours of the sphenoidal ridge and of the posterior fossa, including all those in the cerebello-pontine angle that could be removed satisfactorily.

There were 18 recurrences after such resections. Fourteen have been confirmed at operation or necropsy; in the other four the diagnosis rests on clinical findings-fairly securely in three, but much less so in the fourth. This gives a recurrence rate of $16 \%$, or $19 \%$ if cases treated in the last five years are excluded. The average time elapsing before confirmation of recurrence (in verified cases only) was 59 months, the extremes being 13 years and 26 months. It is worth noting that of all the recurrences after operations of Grades I and II, only four came with a latent period of 10 years or more, and none exceeded 15 years. This is not to say that much delayed recurrence is impossible. The literature contains instances. But it does appear uncommon: there are enough long survivals in the London series to have provided examples if it were not.

In Table II operations of Grades I and II are compared. The superiority of a Grade I operation, i.e., a sinus resection, with parasagittal tumours is, of course, self-evident. It must be emphasized, moreover, that the operations of Grade II include none in which an obviously invaded sinus was left untreated: such operations are all classed in Grade III. All these Grade II resections appeared satisfactory resections to the surgeons responsible, and there were indeed many cases in which an entirely favourable prognosis was given. Table II also shows the frequency of recurrence of the basal tumours; it appears relatively high both with operations of Grade I and Grade II, which suggests that where there is no question of a major sinus being invaded, the diathermy current is a reliable weapon.

The remaining operations, those of Grades III, IV, and V, cannot be considered radical, and it may be supposed that cases so treated will inevitably develop symptomatic recurrences, soon or late. 
Practical interest centres on the factor of time: these less ambitious resections have given a few very prolonged survivals. From the biological standpoint they also give a better concept of the growth rate of the meningiomas than can be obtained in any other way.

The 24 tumours treated by operations of Grade III had, by definition, dural or extradural extensions which were not resected. In the majority these were osseous: notably, nine were sphenoidal ridge tumours en plaque, with hyperostosis too extensive for complete removal. Six were parasagittal tumours: in these, either the operation spared a venous sinus known to be invaded, or it was carried out with no attention to the possibility of such invasion. In the whole group there have so far been three verified recurrences and four unverified, but almost indubitable. An eighth case is also at present under suspicion. This is an incidence of only $29 \%$. Moreover, the graph of survivals (Fig. 1) shows a few very good long-term results, mostly with patients in whom the residue is hyperostotic bone. Sphenoidal ridge tumours en plaque have indeed done well; there may be radiological evidence of continued growth over the years, but in only one case has there been a serious recurrence.

In 51 cases, resection of the intradural tumour was frankly incomplete. The operations ranged widely in magnitude, from those in which the residue was estimated as " only a thin shell" or " a couple of tags", to those in which at least half the tumour was left in situ. Necropsies have, however, shown that such estimates are wholly unreliable, and no effort is made to subdivide these resections, which are all classed in Grade IV. Various reasons dictated these incomplete procedures: most common was a fear of injuring the great branches of the circle of Willis. When the vascular relations of the tumour are so intimate a total eradication may be really impossible, and it is therefore of importance to know the probable results of subtotal operations. There have in fact been 20 recurrences after operations of Grade IV, mostly fatal, and in 12 instances unverified. This gives a recurrence rate of $39 \%$, or $44 \%$ if cases treated in the last five years are excluded. Intercurrent disease appears to have carried off several other patients who might be expected to have died of continued growth had they lived longer. A further hazard not brought out by these figures is that the incompleteness of a resection may in itself be a danger; several post-operative deaths came from brain-stem compression unrelieved by the partial excision of a deep-lying tumour. For all this, the limited resections have given a few pleasing results. Thirteen patients $(26 \%)$ have lived 10 years or more; nine of these passed 15 years. The London series provides two instructive illustrations of the indolence sometimes exhibited by these tumours. One man had a sphenoidal ridge tumour, of global type, about $5 \mathrm{~cm}$. in diameter, adherent to the cavernous sinus and infiltrating into the pterygoid region. It was found impossible to remove it all, and the surgeon responsible believed that the residue (which he charred with the diathermy electrode) represented a quarter of the whole. It was naturally feared that the patient would die from his tumour. In fact, however, for 18 years, he lived and died of an accident; necropsy showed a residual meningioma no larger than a walnut. The other case was a woman with a suprasellar meningioma. About two-thirds of this, by operative estimate, were removed in 1935. She was left with severe visual loss, but there is no evidence that this progressed, nor any record of other complaints, until her death (suicidal) in 1955. Necropsy showed a massive suprasellar meningioma; this must have been silently growing for the previous 21 years, but was still not dangerous to life.

Simple decompression alone (operation of Grade V) may occasionally prolong life. It was the resort in a few cases, usually because of torrential bleeding. Nine survived more than six months, and two of these lived for seven and nine years respectively, before developing symptomatic recurrences.

Some prominence has been given to these cases, because they illustrate the extreme variations in the natural history of the meningiomas. The indolence exhibited by some is exemplified by these long survivals: on the other hand, one of the frankly malignant recurrent tumours grew in 13 months from a vestige invisible to the eye to a mass $6 \times 5 \times 4 \mathrm{~cm}$. in size. This variability in the natural history of the disease makes the general evaluation of any form of treatment difficult. It also makes the possibilities of predicting the growth-rate of a particular tumour of great clinical interest.

\section{The Pathological Basis of Recurrence}

The 246 cases in the Oxford series have given material for an analysis of the pathology of the meningiomas. In 198 cases there are the operative descriptions, often illustrated, and the biopsy specimens; in $\mathbf{4 1}$ there are also the records and specimens from necropsies done at varying times after operation; and seven cases came to necropsy without previous operation. Some of our patients died in remote hospitals, and it is likely that in several instances infiltration of adjacent structures escaped record. For this reason, the figures to be reported probably underestimate the infiltrative powers of the tumours. 
The general pathology of the meningiomas has been frequently described, and it would be impossible to amplify such magnificent studies as that of Henschen (1955). There are, however, certain points relevant to the recurrence of these tumours which need emphasis.

First, their gross anatomy can make a total eradication extremely difficult. When they are smooth-surfaced, enucleation is easy; when they are nodular, as was the tumour shown in Fig. 2, a nodule embedded in brain can be detached and overlooked. Good technique will, however, usually avoid this. A similar danger is presented by the tendency of global meningiomas to form miniature plaquelike extensions in the subdural space. This was found in at least 21 cases $(8.5 \%)$, excluding those 11 meningiomas wholly en plaque in form. Usually the subdural extension is a thin, flat fringe extending from the periphery of the dural attachment for a centimetre or so, lying on but not infiltrating the arachnoid (Fig. 3). This fringe can adhere to the maninges after the removal of the main tumour. This has been actually seen to occur. A vestige of such a fringe, if it were viable, would probably lead to a recurrence centred on the margin of the original tumour, a situation in fact occupied by several of the

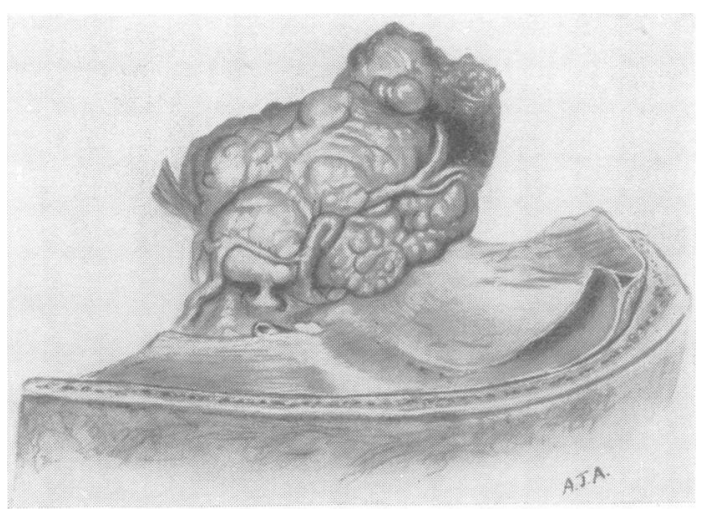

FIG. 2.-A sphenoidal ridge meningioma, showing the characteristic nodularity and the intimate relationship with the vessels of the circle of Willis.

recurrent meningiomas in this series. In several cases the subdural fringe was much thicker and farspreading, even in one instance flowing over the whole hemisphere from base to midline.

But these formations (seen particularly with the superficial tumours) are comparatively innocuous. Far worse manifestations of the tendency of meningiomas to burrow along favourable tissue planes are

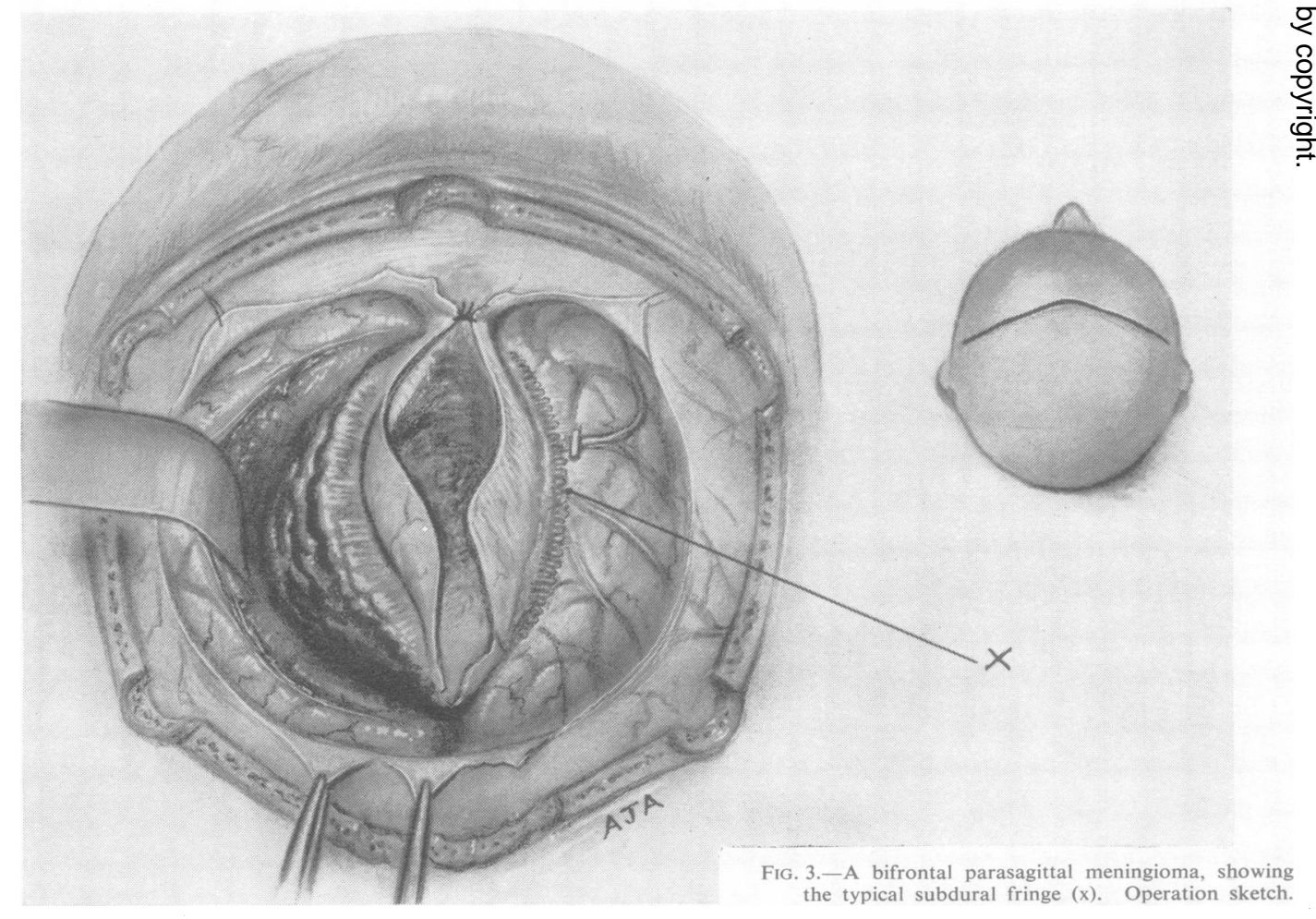


seen with the basal tumours. These are, as is well known, apt to envelop the great vessels of the circle of Willis, the cranial nerves, and the hypothalamus. This behaviour may make such tumours obviously inoperable. It could also defeat an apparently successful operation: unobtrusive extensions through the tentorial hiatus, around the carotid artery, or anterior to the pons might again be overlooked. There is, however, no definite evidence that this did occur in this series; what did happen on a number of occasions was catastrophic injury to great vessels, caused in an attempt at a perfect removal. This accounted for at least eight of the 30 operative and post-operative deaths in the Oxford series.

These are all expressions of non-infiltrative growth. It is, however, to be emphasized that the meningiomas, even those in other respects most benign, are also capable of infiltrative growth. The dural attachments were invaded in a very large number of cases. It is indeed wise to assume that there is always dural penetration, although in a few instances none was actually seen in a limited examination. Usually the dura wide of the actual area of attachment is uninvaded; but rarely the meningioma cells may spread more diffusely and invade dura that is to the naked eye normal. However, this is a highly unusual misfortune.

Invasion of a great dural venous sinus was confirmed in 34 cases $(14 \%)$, and very strongly suspected in a further six. In the majority, it was the superior longitudinal sinus. Invasion of this vessel was found

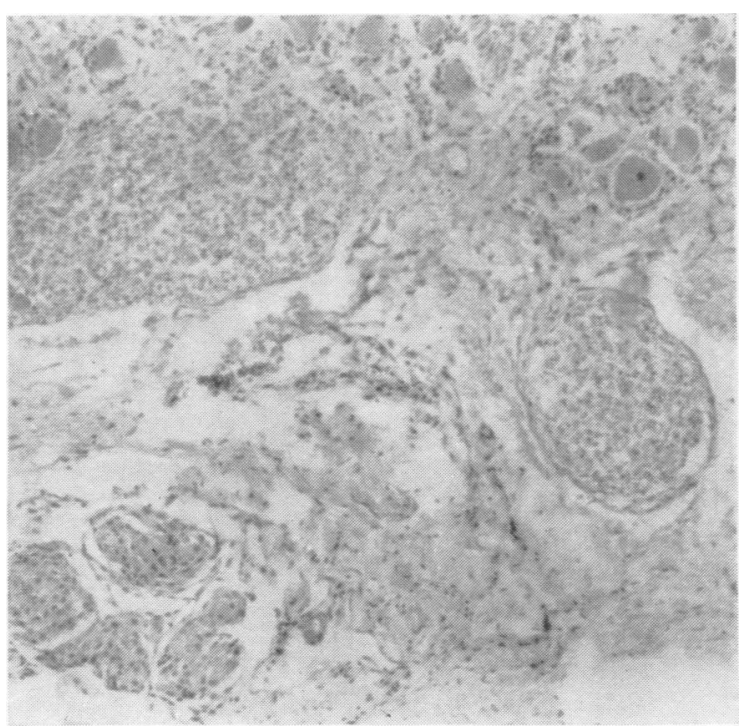

FIG. 4.-A meningioma of the sphenoidal ridge invading the cavernous sinus and the walls of the trigeminal ganglion.

(Haematoxylin and eosin $\times 90$. in about $40 \%$ of the parasagittal tumours, and, as will be seen, accounts for many recurrences after operations of Grade II. Involvement of transverse, sigmoid, and cavernous sinuses was, however, not uncommon. In Figs. 4 and 5 sections of a very welldifferentiated meningioma are seen, invading the cavernous sinus and even the walls of Meckel's cave.

Besides this manifestation of intradural spread, the meningiomas also exhibit transdural growth, and particularly relevant is their tendency to grow across the great dural septa, the falx, and the tentorium. This was found in 25 cases $(10 \%)$, and this may well be an underestimate. Such spread is referred to here as trans-septal extension, and is considered to be of much importance.

Invasion of bone is a commonplace finding. In this series there were hyperostoses in some 79 cases and bony erosion in 21 ; there were thus gross bony abnormalities (usually visible radiologically) in $36 \%$. In 50 cases there was microscopical proof of infiltration of bone, and this again is certainly an underestimate, because not all the hyperostoses were examined adequately. Fig. 6 shows a typical conical endostosis, partially (but not wholly) permeated by a fibroblastic meningioma, microscopically of apparent innocence (Fig. 7). Beside bone, many other extradural structures may be penetrated. The orbital cavity was invaded in seven cases, the

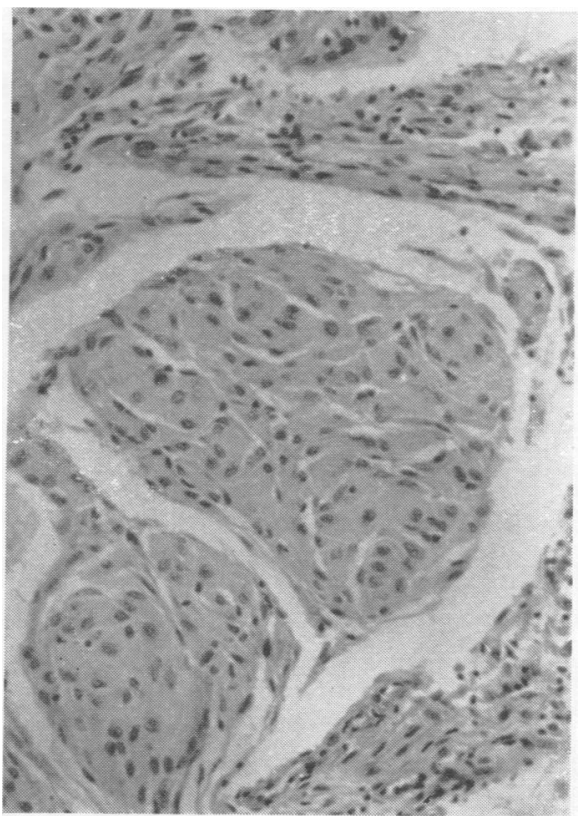

FIG. 5.-The same tumour. It is of endotheliomatous type, well differentiated and apparently of slow growth-rates.

(Haematoxylin and eosin $\times 210$.) 


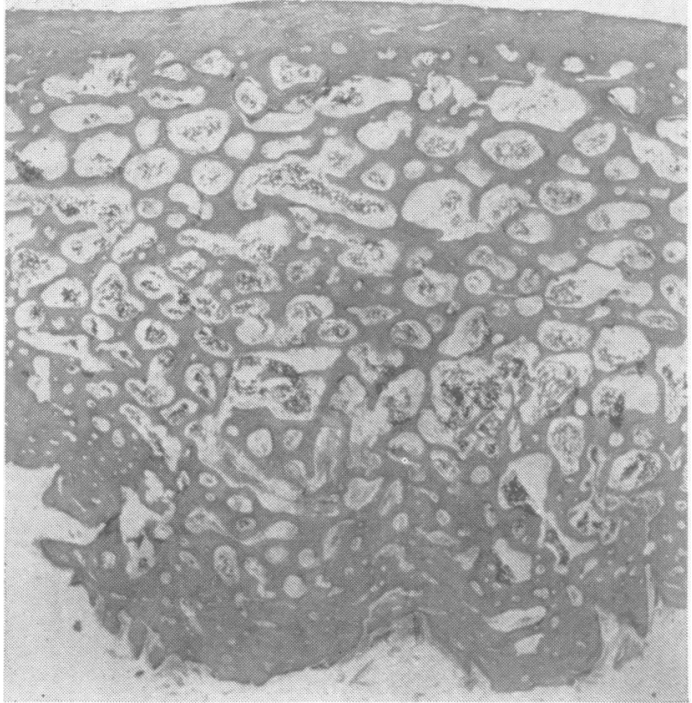

Fig. 6.-The hyperostosis overlying a meningioma of the cerebral convexity. There is penetration by tumour cells.

(Haematoxylin-Van Gieson $\times 5$.)

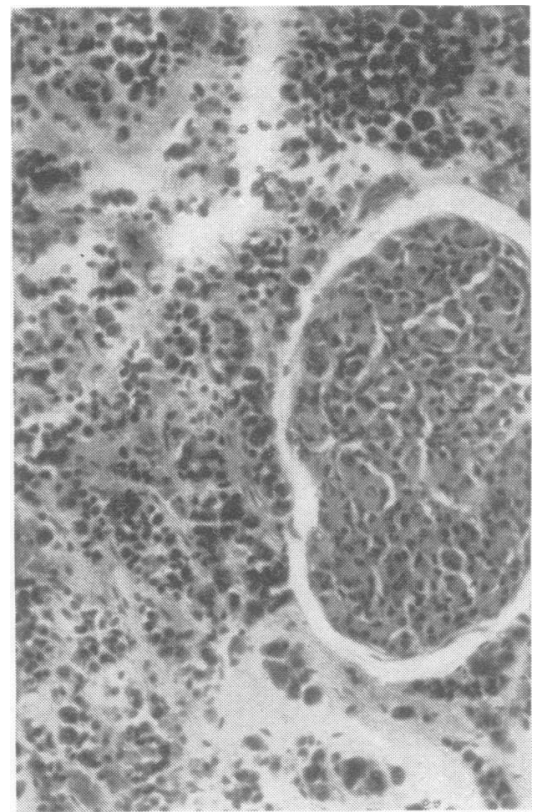

Fig. 8.-Invasion of the anterior pituitary by a subtemporal meningioma.

(Haematoxylin and eosin $\times 210$.)

temporalis muscle in six. The paranasal air sinuses were involved in five cases, the middle ear in two. In one of the latter there was finally a neoplastic polypus in the external auditory meatus, reminiscent

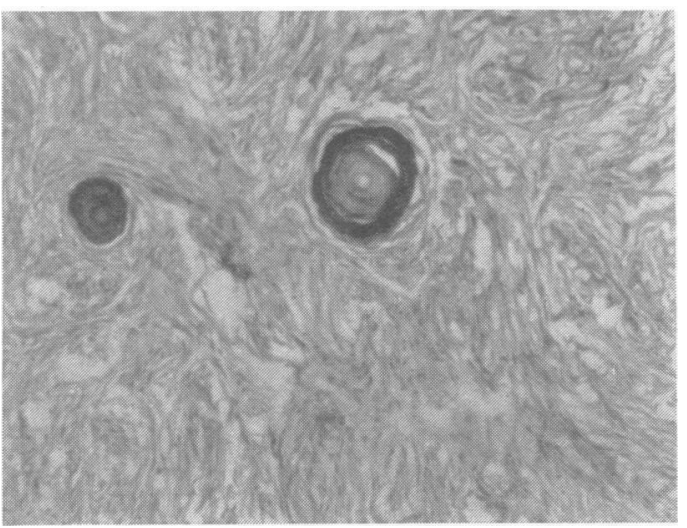

Fig. 7.-The same tumour. It is of fibroblastic type, well differentiated and apparently of very slow growth-rate.

(Haematoxylin-Van Gieson $\times$ 90.)

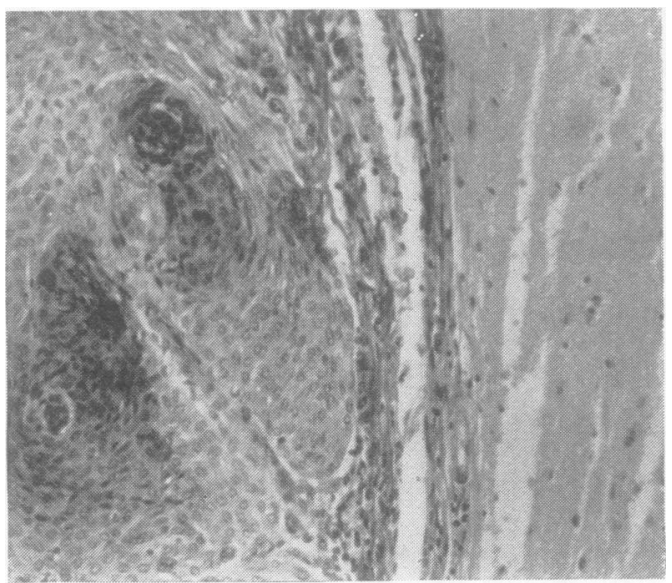

Fig. 9.-A well-circumscribed meningioma and the adjacent brain. (Haematoxylin-Van Gieson $\times 160$.)

of a jugular glomus tumour. The anterior pituitary itself was invaded in one case (Fig. 8).

Finally, the brain may itself be invaded. This was denied by some of the earlier pathologists, notably Penfield (1932), but it is incontestable. Usually the meningiomas were found clearly defined from brain, often by a " capsule" of flattened leptomeninges, as seen in Fig. 9. In nine cases $(3.7 \%)$ there was no such definition, but on the contrary a limited infiltration of the brain tissue. Fig. 10 shows a fine example. Kalbfleisch and Grebe (1937) justly present this as a possible cause of recurrence but it may at once be said that its importance is limited. It is not only rare, it is also less dangerous in practice than would be thought. The digital processes of tumour tend to adhere to the main mass, and in the case from which Fig. 10 was taken a complete removal 


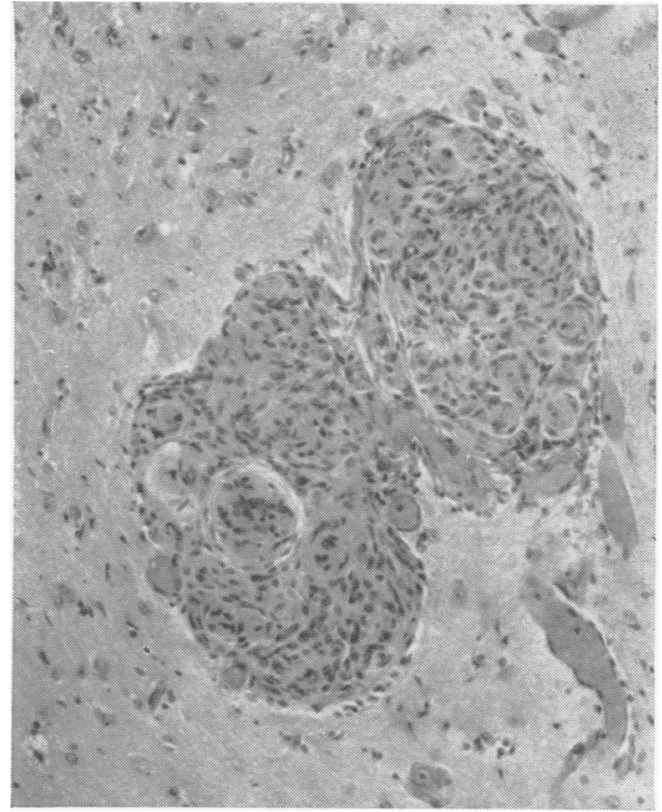

Fig. 10.-Invasion of the brain by a meningioma of the cerebral convexity, not otherwise of malignant type (operation specimen). (Haematoxylin and eosin $\times 160$.)

was in fact effected-complete as evidenced by numerous sections made at necropsy through the tumour bed.

These manifestations of invasive growth have been given at length, because they appear to have been responsible for most of the recurrences in this series. They also show how far from benign, in the strict sense, the meningioma can be. Blatant malignancy was indeed presented by two tumours, which metastasized. One was a parasagittal meningioma, excised elsewhere, and treated here because of a local recurrence. A Grade II resection was carried out, apparently successfully, but the patient died two years later with generalized visceral metastases, in lungs, liver, kidneys, and elsewhere. There was only a minute intracranial recurrence at necropsy. This case is to be published in full by Professor E. A. Linell, who has kindly allowed a preliminary report (Linell, 1955, personal communication). The second case may be given in a little more detail because, besides its interest as an instance of metastasis, it is a microcosm of the problem of recurrence (Case 6 in Table V of Linell's series).

\section{Illustrative Case Report}

Catherine C. (R.I. No. 196859), aged 56, was first admitted on September 27, 1954.

She complained of headaches over the previous three years and more severely over the previous two months, with recent mental confusion.

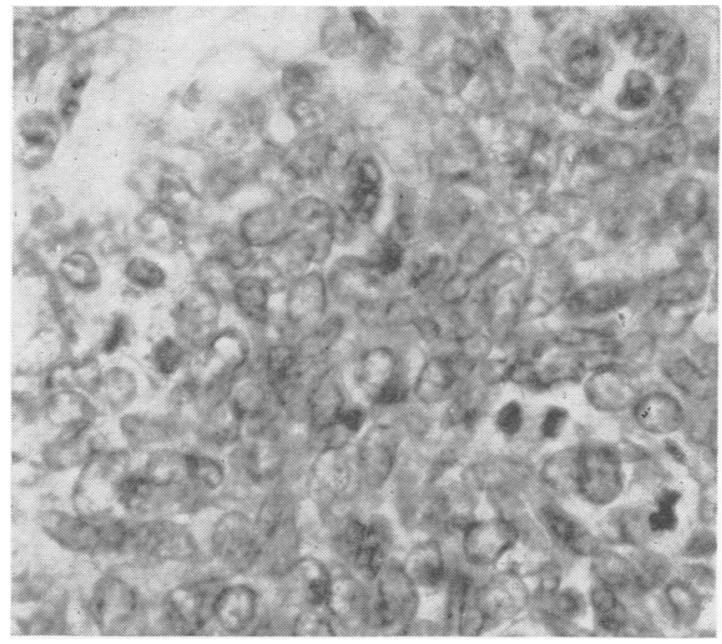

FIo. 11.-A parasagittal meningioma with microscopic evidences of very active growth. Considered to be a very anaplastic fibroendotheliomatous tumour, although evidence of fibroblastic activity is lacking in this section.

(Haematoxylin-Van Gieson $\times$ 470.)

On examination she was drowsy, mildly demented, and with a slight dysphasia; there was a minimal right hemiparesis. There was papilloedema.

Angiography showed a left frontal vascular tumour, and the pathological diagnosis was of a meningioma, though some doubt was expressed over its innocence, because the arterial phase showed some rather irregular vessels.

At operation on October 5 a Grade I excision of a parasagittal frontal tumour was performed. To the naked eye, this was a typical meningioma, if rather lobular, and it attached in characteristic fashion to the superior longitudinal sinus, invading without occluding it.

Histologically (Fig. 11) the tumour was an extremely anaplastic growth, with many mitoses but fairly isomorphous cells. Glycogen was present in many areas, and also collagen, and there was some reticulin. It was considered a meningioma, and microscopically of very rapid growth. It was feared that it would prove malignant.

The patient tolerated the resection of the frontal quarter or so of the superior longitudinal sinus well, and remained in good health for 12 months. She was readmitted on November 15, 1955, however, because of headaches and progressive dementia developing rapidly over the previous two weeks.

On examination she was drowsy, apathetic, and demented, more so than when first admitted. There was no papilloedema, but the decompression bulged. There was now a left hemiparesis and bilateral grasp reflexes.

Angiography showed a vascular bifrontal tumour, much as before.

At operation on November 22 a Grade I recurrent, mainly left-sided bifrontal tumour was resected, with $2 \mathrm{~cm}$. of the remaining falx and sagittal sinus.

Histologically the appearances were similar, but the signs of malignancy were even more marked. 


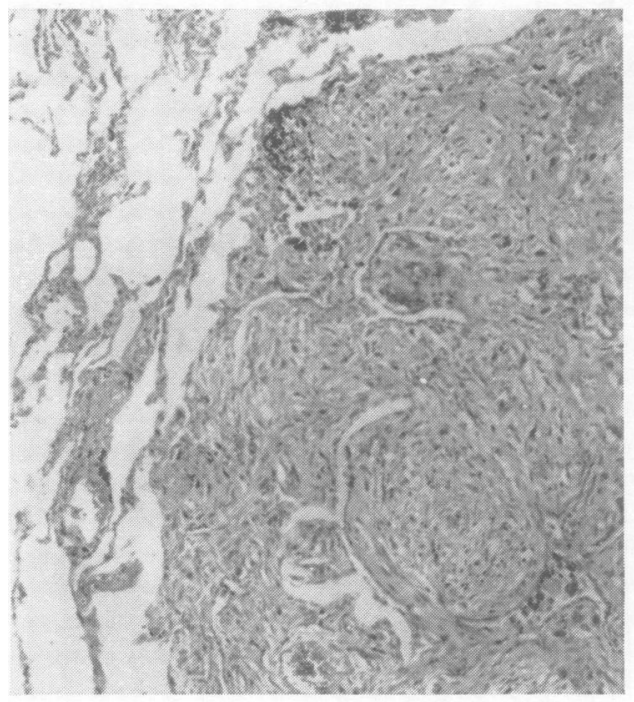

(a)

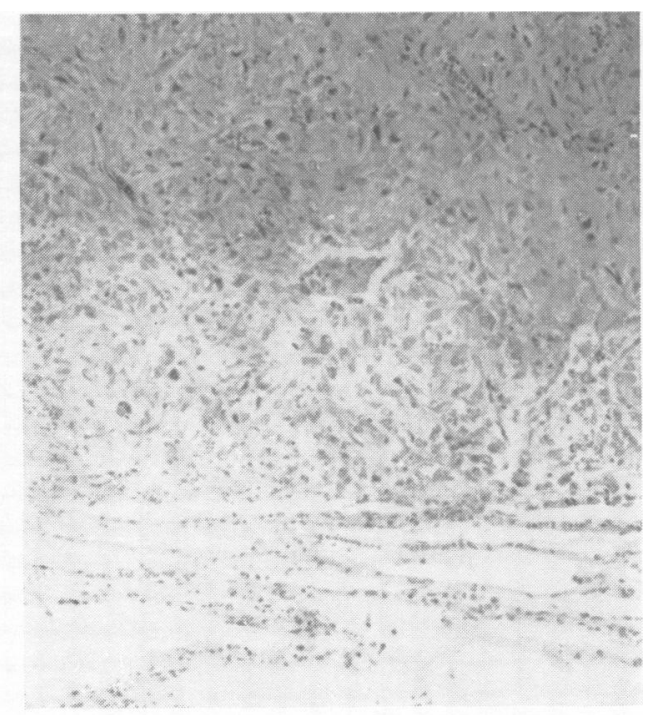

(b)

FIG. 12.-An angioblastic meningioma of the cerebral convexity, also clinically benign. (a) Haematoxylin and eosin $\times 210$. (b) Reticulin $\times 210$.

Post-operatively the patient this time failed to improve, whether because of interference with the frontal venous drainage or from some other cause is obscure. She remained stuporose and died on January 10, 1956.

Necropsy.-This showed no macroscopic or microscopic intracranial residue of tumour nor any primary growth elsewhere. There were, however, in the lungs three small nodules, the largest $8 \mathrm{~mm}$. in its greatest diameter. Two were sub-pleural, one deep in the lung parenchyma.

Microscopically they are identical: they show spindle or polygonal cells, somewhat pleomorphic, and with much collagen in the stroma (Figs 12a, 12b). They do not exactly resemble the intracranial growth, but are nearly related to it. The possibility that they are all independent malignancies, or even that the intracranial tumour is a metastasis from one of them, has of course arisen: but Professors D. S. Russell and R. A. Willis, who have very kindly examined the microscopic preparations, concur in believing this most unlikely.

The purely histological study of the meningiomas has present relevance only as an index of their biology and particularly of their disposition to recur. Classifications based on character of tissue differentiation, of which there are many (Henschen (1955) gives a full review), have generally proved of little value. In this study, the tumours were at first classed as endotheliomatous, fibroblastic, fibro-endotheliomatous, angioblastic, and undifferentiated. This system derives from the well-known classification of Bland and Russell (1938), and as far as possible the criteria were theirs. It differs in that no separate identification of xanthomatous and myxomatous types is made, and in the recognition of the "undifferen- tiated " meningiomas. Table III shows the distribu tion of these types, and their relation to recurrence

TABLE III

Фิ 음

HISTOLOGY AND RECURRENCE IN THE OXFORD SERIES (EXCLUDING 17 UNCLASSIFIABLE TUMOURS)

\begin{tabular}{l|c|c|c|c|c}
\hline & $\begin{array}{c}\text { Endo- } \\
\text { thelio- } \\
\text { matous }\end{array}$ & $\begin{array}{c}\text { Fibro- } \\
\text { endo- } \\
\text { thelio- } \\
\text { matous }\end{array}$ & $\begin{array}{c}\text { Fibro- } \\
\text { blas- } \\
\text { tic }\end{array}$ & $\begin{array}{c}\text { Angio- } \\
\text { blas- } \\
\text { tic }\end{array}$ & $\begin{array}{c}\text { Undif- O } \\
\text { feren- } \\
\text { tiated }\end{array}$ \\
\hline $\begin{array}{c}\text { Total no. in the } \\
\text { series }\end{array}$ & 132 & 39 & 37 & 12 & 5 \\
\hline $\begin{array}{c}\text { No. recurring after } \\
\text { radical operation }\end{array}$ & $\begin{array}{c}12 \\
(3 \text { twice) }\end{array}$ & 3 & 2 & - & $\begin{array}{c}2 \\
\text { both } \\
\text { twice) }\end{array}$ \\
\hline $\begin{array}{c}\text { Average survival } \\
\text { before confirma- } \\
\text { tion, or diagnosis } \\
\text { in unverified cases } \\
\text { (counting individ- } \\
\text { recurrences } \\
\text { separately) }\end{array}$ & $\begin{array}{c}5 \cdot 7 \\
\text { years }\end{array}$ & $\begin{array}{c}2 \cdot 3 \\
\text { years }\end{array}$ & $\begin{array}{c}8 \cdot 2 \\
\text { years }\end{array}$ & - & $\begin{array}{c}4 \cdot 75 \\
\text { years }\end{array}$ \\
\hline
\end{tabular}

It may at once be said that this classification is of little biological significance, either in relation to the incidence of recurrence, or the disposition to infiltrate. None of the major groups has a monopoly of malignant behaviour or of innocence, except that the angioblastic meningiomas as here defined appear particularly benign (vide infra). Only the small group of undifferentiated meningiomas has peculiar properties.

It is indeed notable that in each histological type there are tumours varying widely in apparent activity of growth, forming as it were a continuous spectrum. There are well-differentiated endotheliomatous tumours, with whorls and lobules of cells recalling arachnoid villi, and all the microscopic 

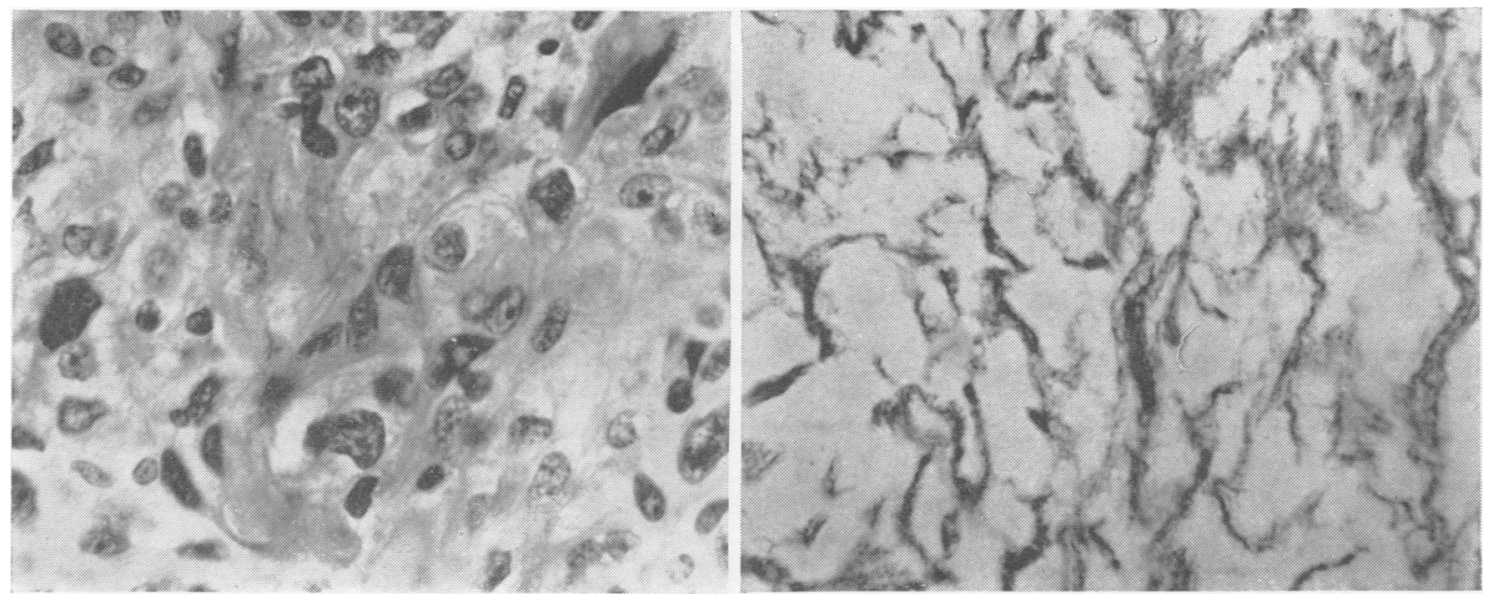

(a) Haematoxylin-Van Gieson $\times 70$.

(b) Haematoxylin and eosin $\times 160$.

appearances of indolent growth. (Fig. 5 shows an example.) But there are also a few tumours in which, though the cell type and cellular pattern permit classification as endotheliomatous, there is much nuclear pleomorphism and many mitoses. Similarly, the highly fibroblastic tumours show all grades between the well differentiated growth of Fig. 7 and the highly anaplastic tumour seen in Fig. 13. The angioblastic tumours are less easily summed up. Some resemble, and are probably allied to, the better-known cerebellar capillary haemangioblastomas (Fig. 14). Others show more mature vessels, and could be called angiomatoid (Fig. 15). Despite the frequent presence of giant cells, both these groups appear microscopically of slow growth and behave innocently. This may appear surprising,

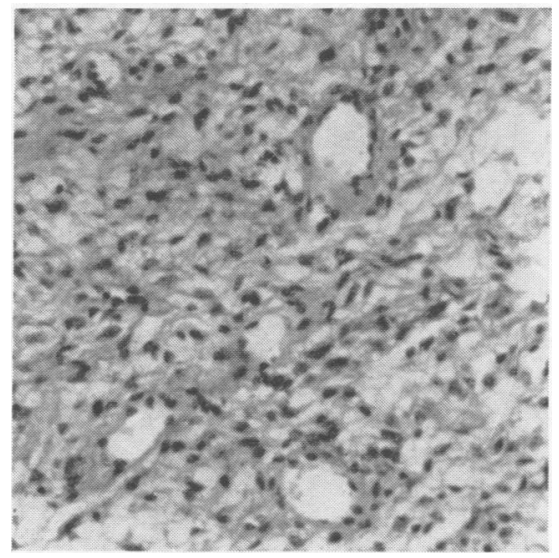

for the angioblastic meningiomas have always had a certain notoriety (Bailey and Bucy, 1931). This is perhaps because most writers have comprehended as angioblastic tumours here designated undifferentiated.

In this series there were five tumours of peculiar and uniform character. To the naked eye they were typical, rather vascular meningiomas, in conventional sites-subtemporal, parasagittal, cerebellopontine, frontal cerebral, and cerebellar convexity respectively. Under the microscope, they are seen to be highly cellular and quite without organization (Fig. 16a). That is to say, they shcw neither

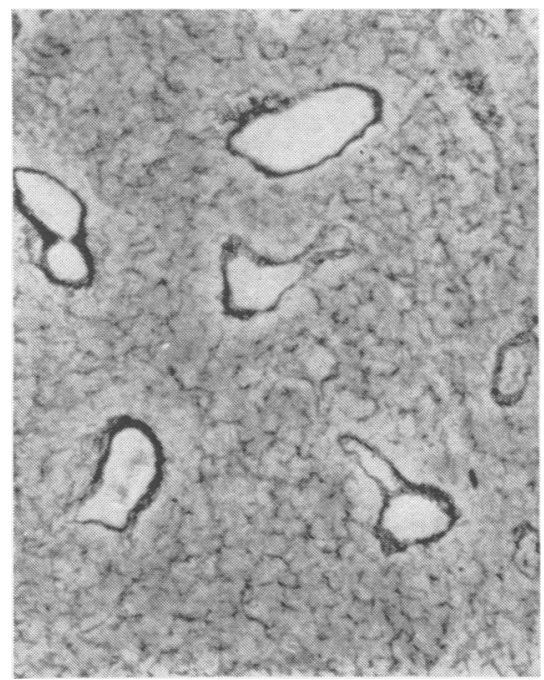

FIG. 14.-A fibroblastic meningioma appearing to be of very rapid growth.
(a) Haematoxylin-Van Gieson $\times 470$. 


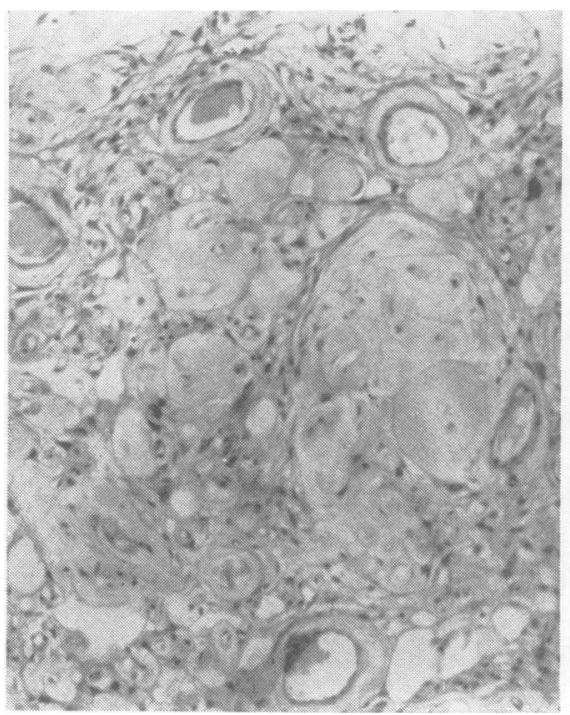

(a)

(b)

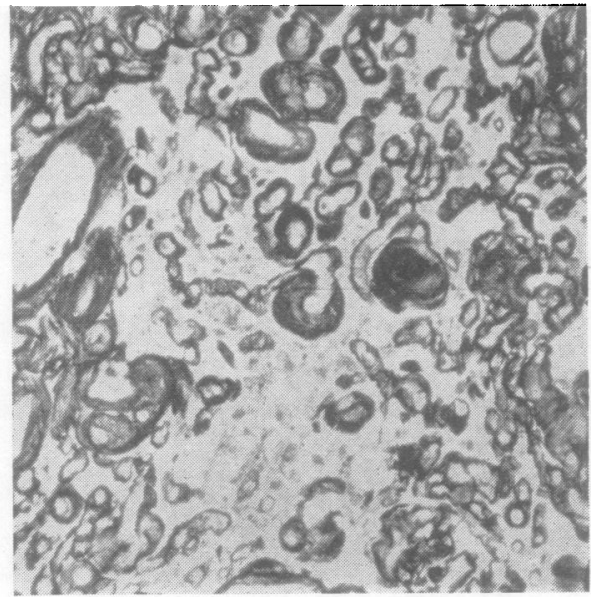

FIG. 15.-An angioblastic meningioma of the Sylvian fissure, clinically benign. (a) Haematoxylin-Van Gieson $\times 210$. (b) Reticulin $\times 210$. whorls, laminas, nor lobules. The cells are fairly uniform, and in shape fusiform or multangular (Fig. 16a). Mitoses are seen in all five, and are very numerous in two. Collagen is occasionally present, but much more impressive is the diffuse network of reticulin seen throughout the substance of the tumour (Fig. 16b). Several show immature vessels, and this, together with the reticulin structure, at first suggested that the little group represents an anaplastic variant of the angioblastic meningioma. This may indeed be so, but no connecting transitional forms have been found, and the vasoformative tendency is not constant. Any rapidly growing

Fig. 16.-An undifferentiated meningioma of the cerebral convexity. This tumour is the only one of this type which has not recurred as yet.

(a) Haematoxylin and eosin $\times 210$. (b) Reticulin $\times 210$. (c) Haematoxylin and eosin $\times 470$.

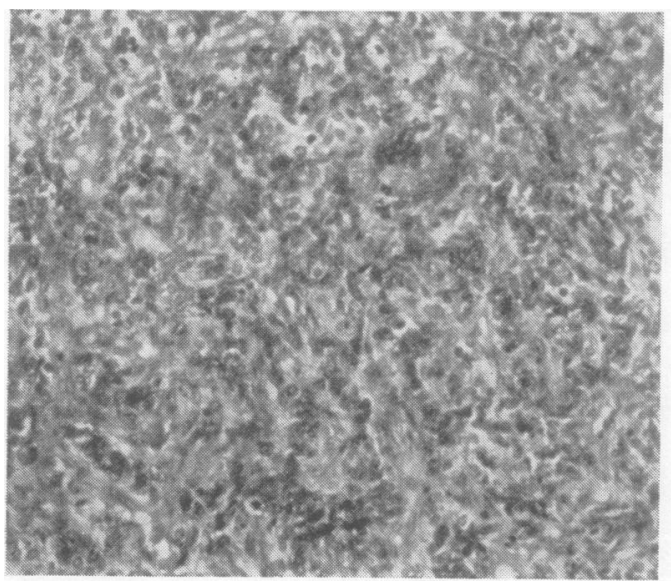

(b)

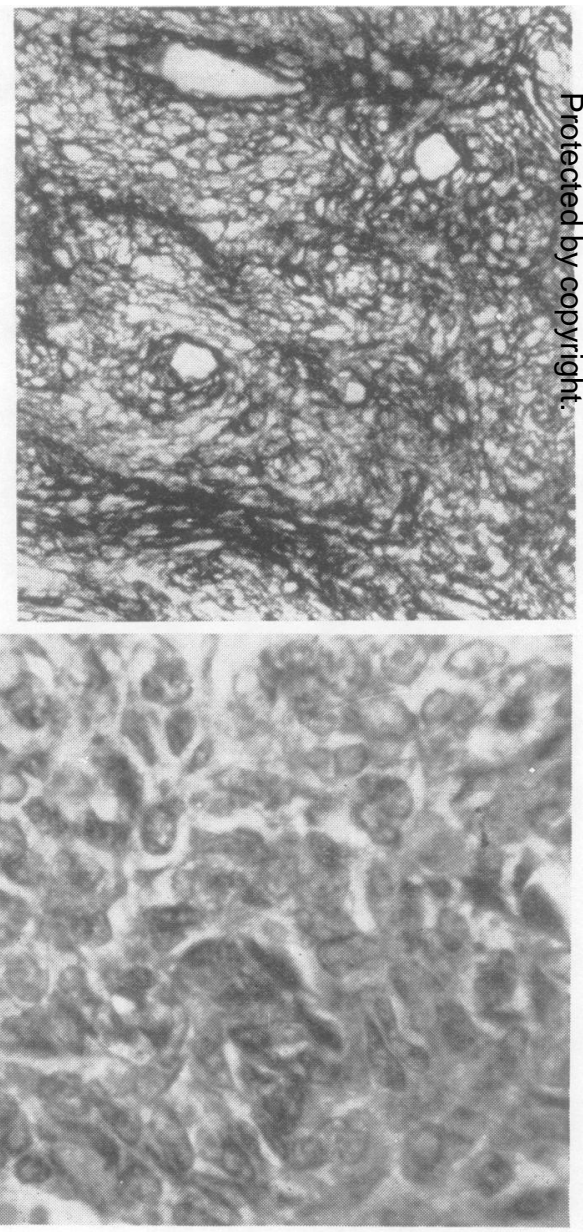

(a) 
tumour may show poorly formed vasculature, and it seems best to designate as angioblastic only those tumours in which the formation of vessels appears the chief and specific tissue differentiation. Other terms were considered, but at present some noncommittal expression seems best, and they are referred to here as " undifferentiated". Globus (1937) designated tumours apparently of similar histology " meningiomas indifferentiale". It seems particularly important to separate them from other meningiomas, and especially from the angioblastic meningiomas, because the prognosis is much worse. In two patients in the small group the tumours have recurred fatally after radical excisions, one with widespread terminal haematogenous metastases (vide supra). Two other patients have died following subtotal resections, one tumour recurring very rapidly after a Grade III resection. Only one patient still lives.

It will be seen that no attempt has been made to separate the biologically malignant meningiomas on purely microscopic grounds. Many writers have done this, notably Craig (1927) and Turner et al. (1942). But Henschen (1955, p. 486) has very justly pointed out the difficulty of making any exact and constant correlation. The best differentiated, most indolent tumours may be extremely infiltrative, as Figs. 6-8 show. Very anaplastic meningiomas may not recur; very well differentiated meningiomas may do so, or even metastasize, as in Jurow's case (1941). It has appeared from this series that a clearcut microscopic distinction between clinically benign and malignant meningiomas cannot be made. Short of this, however, the microscopic study of the meningiomas has been a very helpful guide to their biological character, and particularly to their rate of growth. Numerous mitoses, lack of regular arrangement, and (though to a much lesser degree) nuclear pleomorphism suggest rapid growth; conversely, regular whorl formation or organization in alveoli or laminae, many psammoma bodies, and an absence of mitoses indicate slow growth. When a tumour is largely but incompletely excised, symptoms due to its continued activity are likely to appear within a couple of years if it is of rapid growth; if it is indolent, recurrence may be delayed 10 years or more. (There are, of course, other factors, notably the size of the residuum and the situation of the tumour.) This is a simple proposition, and reference to Table III shows that it is partially valid. Eight recurrences took place with tumours considered on their microscopic appearances to be rapidly growing. The times elapsing before confirmation of recurrence ranged between four years and 13 months, with a mean of two and a half years. On the other hand, 15 recurrences took place with tumours whose histology suggests average or even slow growth, and with these the mean time interval was six and a half years, with extremes of 13 years and 17 months. It is to be noted that the meningiomas do not often change in their growth pattern. In the majority there is a striking constancy in histological appearance and particularly in growth rate, even after intervals as long as 13 years. On the other hand, at least three tumours did show an apparent deterioration towards greater cytological malignancy, which was borne out by their clinical behaviour.

A final point to be emphasized is the tendency of the meningiomas to multicentric growth. A second primary meningioma, such as the small tumour depicted in Fig. 17, can simulate a recurrence of the tumour originally excised, if close enough to it anatomically. Volynkin (1955) has laid much stress on this, and it is undoubtedly a possibility to be kept in mind. But it is probably unusual. Multiple mengiomas are not common. Luyendijk's (1953) figure of $1.9 \%$ is questionable, as it is not based solely on necropsy statistics; even so, in the small series of cases coming to necropsy here the incidence was only $4 \%$.

With this general appreciation as background, it is interesting to consider the pathology of those 19 tumours which have actually recurred after radical (Grade I or II) resections. In five, two recurrences have taken place, so it is necessary to analyse 24 separate recurrences.

The development of a recurrence must mean either that the initial resection was inadequate, or that the neoplastic change was multifocal, or that viable tumour was accidentally implanted during an otherwise successful resection. In most of these 24 recurrences, there is reasonably clear evidence to indicate that the first, most obvious, explanation is correct. In four, there appears to have been unnoticed trans-septal spread, across the falx in three instances and across the tentorium in one. In eight instances, recurrence probably took place from an invaded falx or superior longitudinal sinus. One patient certainly developed a recurrence from unsuspected invasion of the orbital cavity. In two, perhaps three, instances, there is reason to believe that the recurrence arose from intracerebral vestiges, and the presumption must be that these represented infiltration of the brain. Recurrence from invaded bone, over which Cushing (1938) appears to have been much concerned, seems unusual. In two cases meningioma cells in the bone of the sphenoidal ridge may perhaps have led to recurrences, but proof is lacking. The extreme indolence of an hyperostosis has already been noted. In two other cases recurrences developed which might from their anatomy 


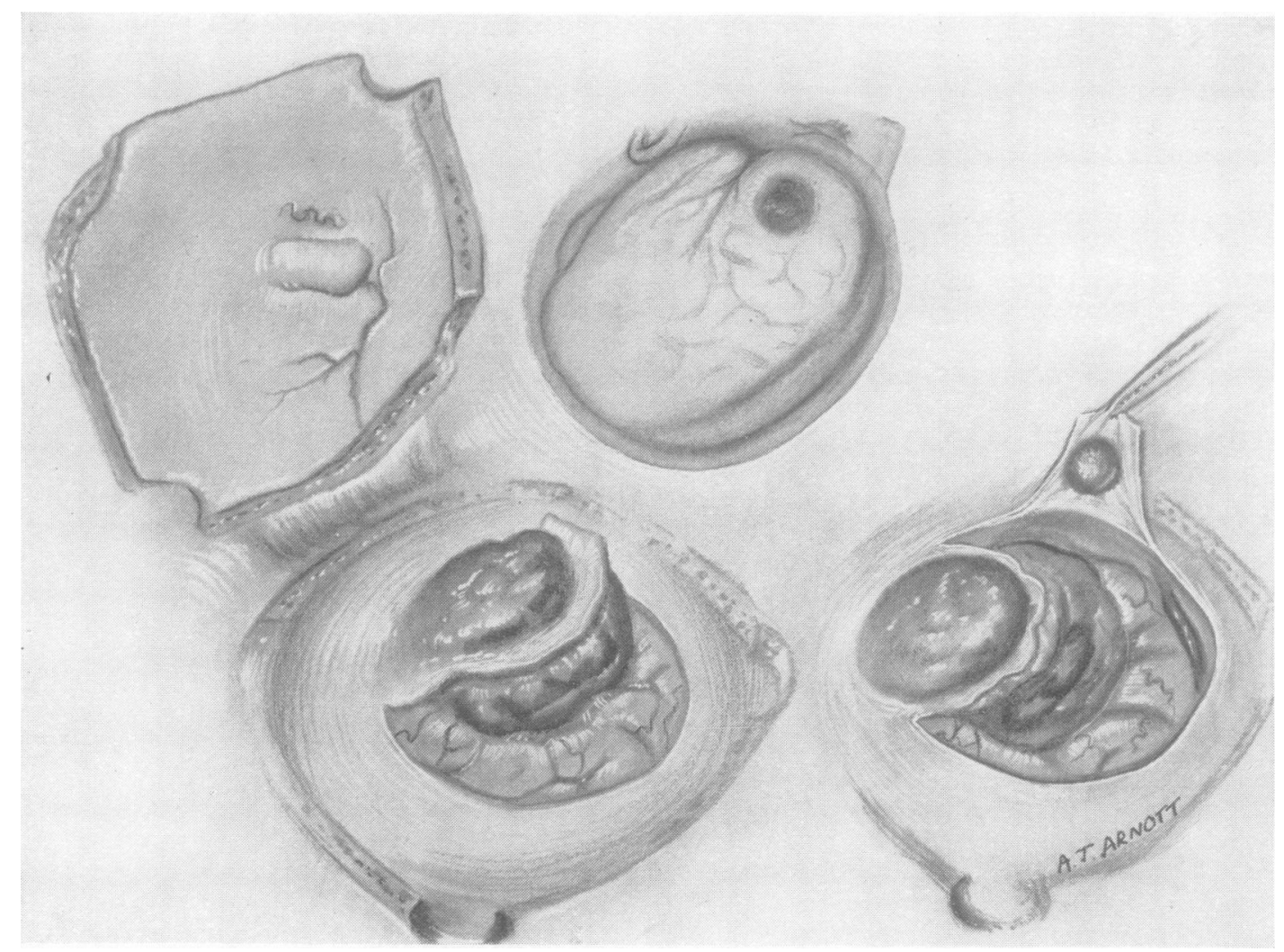

Fig. 17.-Operation sketch of a meningioma of the cerebral convexity; a second small meningioma lies near it, and couid easily escape notice.

have arisen either from an overlooked nodule, or from a fragment of subdural fringe, or from invaded dura: it is impossible to decide.

The two other explanations of a recurrence are hard to confirm or establish. Clear evidence of a recurrence from implanted fragments can only be obtained when the recurrence is in a scar (as in five of Cushing's cases), and this was never seen in the Oxford series. But equally this mechanism cannot be excluded in several of these cases, especially those in which the tumour was removed piecemeal. One such patient died a few days post-operatively, and serial sections showed a minute implant in the tumour bed; but the cells were obviously non-viable, and could not have led to a recurrence. Similarly, the possibility of multiple primary tumours is not always to be excluded. In four instances the recurrence was from two discrete foci. In two of these it is quite possible that one of the recurrent tumours was independent. Both patients had parasagittal meningiomas; each had a recurrence from the invaded falx and sinus and a second recurrence nearby but not really in the original operation field.
These are plausibly regarded as independent primary tumours, perhaps consequent on neoplastic "field" change in a wide area of dura; but they might equally have arisen from vestiges of a subdural fringe on the periphery of the original tumour. There is similar difficulty in interpreting some of the published reports of recurrent multiple meningiomas (e.g., Case 1 of Mufson and Davidoff, 1944).

\section{Conclusions}

The incidence of recurrence will vary somewhat with the experience of the surgeon, and still more with his criteria of what constitutes an adequate operation. Confusion will be lessened if some standard assessment of the scope of the resections is used; the system employed here could doubtless be bettered, but has nevertheless appeared helpful both for individual prognosis and for comparative studies.

The results reported here are probably representative, and they suggest that even with the most radical surgery recurrence is not a possibility to be ignored. When the tumour has been to the naked eye wholly removed, together with its dural attachment and any 
obvious extradural extension (a Grade I resection), it would seem that the surgical ideal has been achieved. Yet in this series the incidence of recurrence in cases so treated was $9 \%$. Where the dural attachment is considered irremovable, as must often happen, it is common practice to coagulate it, even to charring, with the diathermy cautery. If combined with a complete removal of the visible tumour (Grade II resection), this is generally considered an acceptable alternative to the more radical excision; but the incidence of recurrence following such operations was in this series $19 \%$. It is clearly important to distinguish between operations of Grade I and Grade II, both for prognosis and in the presentation of results.

The causes of recurrence are not particularly mysterious, and have been well discussed by Cushing (1938) and others. The material reported here suggests, however, that their relative importance has not always been gauged correctly.

In the first place, there is a tendency to assume that any meningioma which recurs is malignant. Innocence and malignancy are at best relative terms, and become particularly hard to apply with the meningiomas, tumours with which local infiltration is so common and metastasis so rare. By any standards, two of the 19 recurrent tumours studied in this investigation were malignant, since they formed haematogenous metastases. Four other tumours would have been regarded as malignant on histological grounds by many, and certainly their biological characteristic has been aggressive and rapid growth. But in the other 13 there were neither microscopic nor biological peculiarities to distinguish them from the great mass of meningiomas which did not recur.

It is more profitable to consider these recurrences as the expression of a failure in surgery, a failure to eradicate microscopic infiltration or even grosser extension. It seems that unnoticed invasion of the walls of a great venous sinus is the most common cause of recurrence after seemingly successful operations, especially those of Grade II, but even rarely those of Grade I, presumably because the infiltration may be invisible. Unnoticed spread across a free dural septum is also an important cause of failure with Grade II resections. Microscopic infiltration of brain and visible but unobstrusive permeation of the subdural space are probably important though rarer causes of recurrence. Invasion of bone cannot be ignored, but it appears of overrated importance: when one recalls how frequently meningiomas are associated with hyperostosis or bony erosion, it is surprising how rare is a recurrence clearly arising from bone. There is indeed in the behaviour of hyperostoses after
Grade III resections good evidence to suggest that meningiomatous cells in bone are particularly indolent. Nevertheless, trouble may come from invaded bone, especially in the region of the orbit. Finally, surgery may fail when the disease is multifocal: when neoplastic change is not restricted to one point, and there are multiple meningiomas. This would appear comparatively rare, but there is need for further information.

These failures are, of course, often ineluctable: they express the limitations imposed on the surgeon by the need to conserve brain function. It is possible to carry the line of excision through normal tissue when dura and bone are concerned; it is usually not possible to do such a "cancer operation" through normal brain, though Fincher (1954) mentions doing so with one malignant growth. Routine block resection of the great venous sinuses would greatly decrease the incidence of recurrence, but at a prohibitive price in immediate disability or even (Jaeger, 1942,1951 ) in death.

If these propositions are accepted, there are certain practical corollaries.

Surgery should be as radical as is safe. In general, contemporary practice probably goes as far as is possible. There can be no doubt that when a meningioma attaches to the falx or the tentorium its attachment can and ought to be removed. When a meningioma attaches to a great venous sinus the problem becomes much more difficult. A Grade I resection is impossible when the cavernous or the straight (vide Castellano and Ruggiero, 1953) sinus is involved. The transverse sinus can apparently be resected, though this was not done in any case in this series. The superior longitudinal sinus was resected en bloc on only 17 occasions in the Oxford series, and in general the results bear out Olivecrona's (1947) dictum that when the sinus is occluded it may always be excised, but that when it is patent excision is safe only in the frontal third. No question requires nicer surgical judgment than this, and it is significant that Olivecrona's vast experience (Hoessly and Olivecrona, 1955) is making him increasingly conservative. When a meningioma involves bone, the area of macroscopic abnormality ought clearly to be excised, but in this series it has not appeared necessary to boil the bone flap. When a meningioma has actually recurred experience here justifies a second operation on the most radical scale, even at greater hazard than would ordinarily be accepted. This is because of the greater likelihood of a second recurrence. Some very gratifying results have been achieved by such operations. Of the multiple meningiomas, it can only be urged that their possible presence must be kept in mind, especially in interpreting the preliminary radiological studies. 
At the same time it is important to recall that subtotal resection can give very useful palliation; when a radical operation is obviously dangerous to life or to function, a limited procedure may be preferable. This is particularly so with parasagittal tumours, when the posterior portion of the superior longitudinal sinus is invaded but patent. A resection of Grade III may give many years' respite, and permit a later operation of Grade I to be done with impunity when the sinus has become occluded. After subtotal resections generally, there is also a case for irradiation. Most authors deny that these tumours are sensitive, and experience here has on the whole been discouraging. Twenty-eight tumours have been irradiated for various reasons, and although assessment is difficult there has been little evidence of permanent benefit. In one case, there is unhappily proof of detriment, in the shape of a crippling radiation necrosis. Nevertheless, in one or two tumours there appears to have been a slight response, and radiotherapy may perhaps be warranted when excision is certainly incomplete and the meningioma of rapid growth.

Since future recurrence can never wholly be excluded, the pathologist reporting on a biopsy should make his assessment with recurrence in mind. It has appeared in this clinic that the undifferentiated meningiomas are definitely of bad prognosis, and that they should be separately identified. Even more important is an estimate of the growth-rate of the tumour, in making which the presence of mitoses seems of chief moment. Such an estimate, though subjective, has proved of practical value, and is more flexible than an attempt to divide the meningiomas into microscopically malignant and innocent groups. It is possible that the angioarchitecture of the meningiomas, as demonstrated by cerebral angiography, may be correlated with the methods of conventional pathology in obtaining a final assessment of the biological character of a tumour. Lorenz (1940) has described the angiographic appearances of meningeal sarcomas as characteristic. Investigation into this possibility has been begun, but there are many pitfalls, and at present it seems best to reserve judgment.

The clinical diagnosis of a recurrence presents some interesting problems, and can be extremely difficult. Generalization is hard; but it may be said that the recurrent tumours (except those in the posterior fossa) are not commonly associated with the manifestations of raised intracranial pressure. Even the craniectomy decompression (if provided) may be indrawn, and papilloedema is comparatively unusual. Usually the patients' complaint is of some progressive neurological deficiency, motor, visual, or mental, and here diagnosis should usually be easy.
It must, however, be remembered that many of those patients have entered the age-period of arteriosclerosis, and that the bed of a successfully removed məningioma may be a locus minoris resistentiae: progressive cerebral arteriosclerosis may increase a pre-existing neurological deficiency. Still greater difficulty arises with those patients whose only symptom is epilepsy. This is a regrettably common complaint even after a successful excision. It was found in $43 \%$ of cases in the Oxford series. Only in a minority, less than a quarter, did the fits herald a recurrence; in the remainder they were presumably the manifestation of gliosis in the cerebral cortex. A practical guide is in the time relations: the epilepsy of a recurrence is delayed, insistent, and progressively harder to control whereas the epilepsy of gliosis is early in onset (within the first year or so), and tends to diminish in severity as the years go by. There are, however, exceptions to this dictum, and when there is doubt intelligent procrastination is usually warranted. Special neuroradiological investigations will usually give the answer but it must be said in warning that air studies sometimes are deceptive. This is because the recurrent tumour's effect as a spaceoccupying lesion can be offset if there is undue space to be taken up, and this illusion is maintained when the original operation has been followed by local cerebral atrophy. So far angiography has never failed to demonstrate the recurrence, but here too it is possible that an avascular tumour might show no definite displacement of the arterial and venous anatomy. The most important factor in diagnosing these recurrences is awareness of their possibility and as far as can be determined their likelihood. In the average case, recurrence will be unlikely but always possible: unlikely enough to permit reassurance even when minor symptoms cause alarm to the patient, but possible enough to demand sustained, tactful watchfulness.

\section{Summary}

The results obtained in two series of intracranial meningiomas, one of 235 cases and one of 97 cases, are analysed to determine the incidence of recurrence after surgical excision.

A system of grading according to the scope of the resection is presented, and is applied to those cases, 265 in all, surviving more than six months.

Following 90 operations of Grade I, in which the tumour, its dural attachment, and all apparent extradural extensions are resected, there appear to have been eight recurrences $(9 \%)$.

Following 114 operations of Grade II, in which the visible tumour is totally removed, but its dural attachment merely coagulated with the endothermy 
cautery, there were 18 recurrences, or $19 \%$ if cases treated in the last five years are excluded.

These recurrences became manifest after an average period of five years. Long-delayed recurrence, though clearly possible, appears unusual.

After operations known to be incomplete (Grades III-V) the incidence of symptomatic recurrence is naturally much greater, but it is important to note that a number of patients treated by limited excisions have been given long periods of relief.

It is emphasized that in the clinical sense, meningiomas may be benign, locally invasive, or frankly malignant. The frequency of local infiltration is stressed: infiltration of venous sinuses was found in $15 \%$ of cases, of bone in $20 \%$, and of brain in $3.7 \%$. Haematogenous metastasis was seen in two patients.

Histological assessment has proved of much value in predicting behaviour but its limitations are considerable. A small group of undifferentiated vascular, reticulin-forming meningiomas has been identified as particularly unfavourable.

Nineteen tumours recurring after seemingly complete resection are considered. While two were highly malignant and four others showed microscopic signs of rapid growth, 13 were in no way remarkable.

The chief causes of recurrence appear to have been unnoticed invasion of a dural venous sinus, and unsuspected spread across a free dural septum. Detached nodules of tumour, fragments of the subdural fringe often seen in meningiomas, infiltration of bone, and the presence of multiple primary tumours are other occasional causes of recurrence.

The practical implications of these findings, both in treatment and in prognosis, are briefly discussed.

This research was carried out with the aid of a grant from the United Oxford Hospitals. The cases in the London series were made available by the kindness of Mr. D. W. C. Northfield and the Staff Medical Com- mittee of the London Hospital. I am most grateful to Mr. J. Pennybacker and to Drs. P. Daniel and S. J. Strich for much assistance in the preparation of this paper; I would also like to thank Miss A. Arnott, Dr. R. H. Cowdell, and Mr. E. L. P. Tugwell for the illustrations and photomicrographs.

\section{REFERENCES}

Bailey, P., and Bucy, P. C. (1931). Amer. J. Cancer, 15, 15. Ballance, C. A. (1907). Some Points in the Surgery of the Brain and its Membranes. Macmillan, London.

Bland J. O. W. and Russell, D. S. (1938). J. Path. Bact. 47, 291. Castellano, F., and Ruggiero, G. (1953). Acta radiol. (Stockh.), Suppl. 104

Christensen, E., Klaer, W., and Winblad, S. (1949). Brit. J. Cancer, 3, 485 .

Craig, W. McK. (1927). Surg. Gynec. Obstet., 45, 760

Cross, K. R. and Cooper, T. J. (1952). J. Neuropath., 11, 200.

Cushing, H.' With the collaboration of Eisenhardt, L. (1938). Menin-

giomas. Thomas, Springfield, Illinois.
Fincher, E. F. (1954). Surg. Clin. N. Amer., 34, 1037.

Globus, J. H. (1937). Arch. Neurol. Psychiat. (Chicago), 38, 667.

, Levin, S., and Sheps, J. G. (1944). J. Neuropath., 3, 311.

Grant, F. C. (1954). J. Neurosurg., 11, 479.

Henschen, F. (1955). In Handbuch der speziellen pathologischen Anatomie und Histologie. Ed. Lubarsch, O., Henke, F.. and Rössle, R. Bd. 13; Nervensystem, teil 3. S Springer, Berlin.

Hoessly, G. F., and Olivecrona, H. (1955). J. Neurosurg., 12, 614

Hoessly, G. F., and Olivecrona, H. (1955). J. Neurosurg., 12

Horrax, G., and Strain, R. E. (1952). Ann.
Horsley, V. (1893). Brit. med. J., 2, 1365 .

Jaeger, J. R. (1942). Arch. Neurol. Psychiat. (Chicago), 48, 977.

-(1951). J. Neurosurg., 8, 103.

Jurow, H. N. (1941). Arch. Path. (Chicago), 32, 222.

Kalbfleisch, H. H., and Grebe, H. (1937). Arch. klin. Chir., 188, 118.

Kernohan, J. W., and Sayre, G. P. (1952). In Atlas of Tumor Pathology, Sec. 10, fas. 35. U.S. Armed Forces Institute of Pathology, Washington.

Krause, F. (1910-12). Surgery of the Brain and Spinal Cord. (Trs. by Haubold, A., and Thorek, M). Lewis, London.

Laymon, C. W., and Becker, F. T. (1949). Arch. Derm. Syph. (Chicago), 59, 626.

Lima, P. Almeida (1951). Rev. esp. Oto-neuro-oftal., 10, 313.

Linell, E. (1955). Personal communication.

Lorenz, R. (1940). Zbl. Neurochir., 5, 30.

Luyendijk, W. (1953). Acta neurochir. (Wien), 3, 263.

McWhirter, R., and Dott, N. M. (1955). In British Practice in Radiotherapy. Butterworth, London.

Mufson, J. A., and Davidoff, L. M. (1944). J. Neurosurg., 1, 45.

Olivecrona, H. (1947). Ibid., 4, 327.

Penfield. W. (1932). Cytology and Cellular Pathology of the Nervous System, vol. 3, p. 965 . Hoeben, New York.

Rosen, H. J., and Branch, A. (1954). Canad. Serv. med. J., 10, 153.

Shozawa, T. (1952). Gann, 43, 345.

Swingle, A. J. (1949). Arch. Neurol. Psychiat (Chicago), 61, 65.

Taylor, J. (1928). Brit. J. Surg., 16, 6.

Turner, O. A., Craig, W. McK., and Kernohan, J. W. (1942). Surgery, $11,81$.

Volynkin, H. M. (1955). Vop. Nirokhir., 19, 32.

Winkelman, N. W. Cassel, C., and Schlesinger, B. (1952). J. Neuropath., 11, 149.

Zülch, K. J., Pompeu. F., and Pinto, F. (1954). Zbl. Neurochir., $14,253$. 